magnitude as Lorenz's treatment of congenital dislocation of the hip. This is Freyer's operation for enucleation of the hypertrophied prostate glandan operation that has already saved an incalculable amount of human suffering and prolonged many useful lives. At the present time, when there are to be solved so many urgent problems as to hospitals and medical education, it is very necessary to view each problem from every aspect. The question of finance is as serious in the matter of hospital administration as it is in the political world. From the point of view of expense it might be thought that all special hospitals, save those for fevers and the like, should be abolished. On examination, however, it will at once be seen that any sweeping measure to effect such a change would arrest much of the progress of medicine and surgery in this country. From the point of view of the general social welfare the soundness of medical education is the most important consideration. Our large hospitals with their gratuitous service of students and qualified resident officers perform this educational function, and to them falls the bulk of hospital work. But when we consider the position of the physicians and surgeons at such institutions, how they are surrounded by young men eager to learn, and whose minds can receive only the well-ascertained facts of existing knowledge, we see that there is need of a certain number of smaller hospitals which attract only men experienced in the different branches of medicine and surgery, and where the members of the medical staff, being afforded time for reflection, can think out and solve the more advanced enigmas of their work. It has thus been left to a surgeon at one special hospital to discover the proper treatment of the severer degrees of prostatic enlargement, and, but for another special hospital, the only curative treatment of congenital dislocation of the hip would have remained -one knows not for how long-misunderstood and rejected in this country. In medicine the unknown is still greater than the known : the causes, nay, the full meaning of many diseases, from measles to malignant growths, and their remedial medical treatment are yet to find.

1 These photographs, taken from a patient under my care, were first published in Rose and Carless's "Manual of Surgery." " Clin. Soc., December 1905. ' 3 Reports of the Society for the Study of Disease in Children, vol. iv., 1904, pp. 326-327. 4 Pract., November 1905, p. 683. " Reports of the Society for the Study of Disease in Children, vol. v., 1905, p. 290. ${ }^{6}$ Brit. Med. Jour., October 19, 1901. 'Trans. Clin. Soc., 1903, p. 146.

\section{A CASE OF ACUTE HAMORRHAGIC PANCREATITIS.}

A very graphic record of this rare disease is contributed by Dr. Harold V. Munster. ${ }^{1}$ The patient was a man of 54 years. With the exception of occasional attacks of abdominal pain during the preceding three years, he had enjoyed good health. On October 29, 1905, he had to send for medical advice in consequence of abdominal pain. The next day he was found much collapsed, with a pulse of 144 , and complaining much of thirst. Vomiting was frequent, and the vomit often contained "black blood"; the bowels had acted under the influence of castor oil. The temperature was normal. Later, diarrhœa was troublesome, but after a few days the patient improved to such an extent that his recovery was confidently anticipated. Unfortunately, unfavourable symptoms soon appeared-bleeding from the rectum, retention of urine, and delirium. Coma shortly supervened, and death occurred on November 9 -that is, 11 days from the initial seizure.

At the post-mortem examination nodules showing fat necrosis were distributed widely over the peritoneum. The pancreas was much enlarged, and was studded with hæmorrhages, though the gland tissue was by no means obliterated. The tendency to hæmorrhage, as shown by the hæmatemesis, and the discharge of blood from the bowel is a noteworthy feature of the case; also the state of the bowels, constipation at first, followed by diarrhœa. The relatively long duration of the case is also of interest.

$$
{ }^{1} \text { Lancet, Dec. 30, } 1905 .
$$

\section{FURTHER EXPERIENCE WITH DOYEN'S CANCER SERUM.}

Although this serum came upon the stage of therapeutics with a flourish of trumpets transcending the custom even of cures for cancer, there seems to be every likelihood that, like its horde of predecessors, Doyen's serum will be written down a failure. Dr. Alexis Thomson ${ }^{1}$ has just published the results attending the use of this serum in the treatment of inoperable carcinoma. These results are not encouraging, in spite of the fact that one of the patients was seen by Dr. Germain See, Doyen's assistant, and pronounced by him to be a suitable case for the employment of the serum, while all the cases were treated by Dr. Barbour Simpson, who carried out the injections on the lines formulated by Doyen.

The first patient was a woman of 57 , the subject of an extensive recurrence after an operation for the removal of a scirrhous carcinoma of the breast. The breast and axillary contents had been removed seven months before, while two months later the clavicle had been resected for the removal of infected glands from the posterior triangle of the neck. At the time when the serum treatment was begun she presented a combination of cancerous infiltration and of nodules in the vicinity of the scar. She suffered a good deal of pain, but her general health was good, and there was no evidence of dissemination of the growth in the viscera. In the course of a month ten injections were administered. These resulted in several instances in a considerable reaction evidenced by rise of temperature, but there was no improvement in the cancerous condition; the nodules in the skin increased in size so as to become almost confluent, while the pain in the arm became so severe as to demand control by hypodermic injections of morphine. Her general health became rapidly worse, and she died without any vestige of improvement. Cancerous nodules in the skin were 